\title{
Interview
}

\section{Café Philosophique with Lou Marinoff}

\author{
Lou Marinoff, Beatrice Popescu*a \\ [a] EJOP Founding Editor; University of Bucharest, Bucharest, Romania.
}

Europe's Journal of Psychology, 2013, Vol. 9(3), 419-426, doi:10.5964/ejop.v9i3.665

Received: 2013-07-27. Accepted: 2013-07-27. Published (VoR): 2013-08-30.

${ }^{*}$ Corresponding author at: 4-6 Bucur Street, Bucharest, Romania, 040292. E-mail: beatrice.popescu@ejop.org

(i) This is an open access article distributed under the terms of the Creative Commons Attribution License

(http://creativecommons.org/licenses/by/3.0), which permits unrestricted use, distribution, and reproduction in any medium, provided the original work is properly cited.

Beatrice Popescu: First of all, Dr. Lou, we thank you a lot for granting us an interview, considering your busy schedule as a prestigious academic, acclaimed public speaker, writer and last, but not least, philosophical practitioner. Could you please tell us where your love for counseling stems from and who was your first inspiration, aside from the classics?

Lou Marinoff: You are more than welcome, Beatrice. I am delighted to have a virtual coffee with you. My "love of counseling" - as you so generously phrase it - may be nothing more than operant conditioning. My first inspiration was my talkative extended family, most of whom were capable of dispensing advice almost continuously, and on any topic. In such a climate, one must think for oneself, dispense advice in self-defense, and ultimately take one's own counsel. Having counseled myself for many years using philosophical resources, I never dreamed that I would one day do this with others. And today, after more than twenty years of engagement with philosophical practice, it sometimes seems like a dream.

Beatrice Popescu: From a philosophical practitioner's standpoint, philosophy needs to be demystified and made available in the service of people for whom it was initially created. LeBon considers that reaching this goal may only happen progressively, while engaging philosophy therapeutically via five methods that made it famous: critical thinking, conceptual analysis, phenomenology, thought-experiments and creative thinking. Can philosophy (the discipline that discusses anything and attempts to treat any ailment of the soul) become a resource for common people, from the perspective of philosophical counseling?

Lou Marinoff: Yes, and no. I have come to believe that while many people can and do benefit from philosophical counseling, it is not a panacea and may never attract as many people as does psychological counseling. Why? For similar reasons to what we witness in the universities: psychology departments tend to be much larger than philosophy departments, with more faculty and students alike. This is partly because many people find philosophy difficult, which it certainly can be, and find psychology more accessible, which it often is. As to why that is the case, let me offer one plausible reason: For the most part it is fair to say that psychological counselors work mostly 
with affect, whereas philosophical counselors work mostly with reason. Naturally this distinction is not black-andwhite, but it is nonetheless conspicuous.

While everyone is prone to emotional turbulence at one time or another, not all are willing or prepared to make cognitive breakthroughs into the imperturbable realms of the Stoics, the Taoists, and the Buddhists, whose philosophical theories and practices conduce to transcending emotional turmoil, and to converting psychic suffering into serendipity. Most people inherit burdensome psychological baggage from their families, and are further deformed by life's inevitable trials and tribulations. During the $20^{\text {th }}$ century, governments and universities invested heavily in psychology, which developed many schools and modalities for helping people cope with problems of affect. But at the same time, this investment left the masses stranded in their emotions, with nowhere else to turn except to religion or pharmacology. Indeed, one might observe that much of contemporary psychotherapy has itself assumed the status of a secular religion - replete with unexamined premises, unchallengeable dogmas, and institutionalized corruptions.

What we philosophical counselors have discovered empirically is this: A good many people are both desirous and capable of noetic maturation, to an extent that leads them beyond psychotherapy and psychopharmacology alike. Just as Freud castigated organized religions for appealing to and prolonging infantilism in adults, so some philosophers have similarly critiqued psychology and pharmacology for maintaining their patients in arrested states of noetic development, engendering emotional dependencies and preventing people's "inner philosopher" from emerging.

Moreover, as philosophical practice is now burgeoning in East Asia (i.e. China, Japan, Korea), we see Asian practitioners rejecting Western psychology and pharmacology alike as "Western cultural colonialism," and resuscitating indigenous Asian philosophical practices in their stead.

So let's conduct the following thought-experiment: If during the $21^{\text {st }}$ century governments and universities were to invest in philosophical counseling only $10 \%$ as much as they invested during the $20^{\text {th }}$ century in psychological counseling, what would be the outcome? Predictably, more and more of the masses would avail themselves of philosophical services. Services need to be developed and marketed in order to be accessed. I believe that the potential market for philosophy is much larger than most people imagine; yet there will always be people who are neither willing nor ready to explore philosophical pathways. In the best of all possible worlds, people would be made aware of their options, and be able to exercise their preferences.

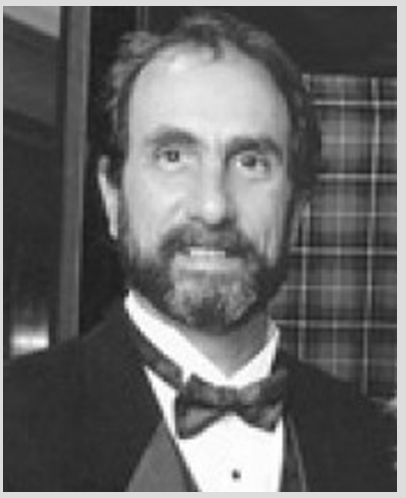

Professor Lou Marinoff is a Commonwealth Scholar originally from Canada, Professor and Chair of the Philosophy Department at The City College of New York, and founding President of the American Philosophical Practitioners Association (APPA). He is also Editor of Philosophical Practice: Journal of the APPA. Lou has authored two international bestsellers: Plato Not Prozac, translated into 27 languages since 1999, and Therapy for the Sane, into 12 languages since 2003. Both books apply Asian and Western philosophy to the resolution of everyday problems. Lou's recent books include The Middle Way (Sterling, NY, 2007), El Poder del Tao (Ediciones B, Barcelona, 2011) and The Inner Philosopher, a dialogue with Japanese Buddhist leader Daisaku Ikeda (Dialogue Path Press, Cambridge MA, 2012). Lou has collaborated with global think-tanks and leadership forums such as the Aspen Institute, Biovision (Lyon) and the World Economic Forum (Davos). Lou is a three-time Canadian Open Table Hockey champion (1978-79-80) and had his comeback in 2007. He is a legend and ambassador of table hockey, promoting the game and sport as highly beneficial for children. Dr. Lou Marinoff is also the publisher of an innovative website (http://www.loumarinoff.com) presenting his own work, either books, photo albums or absolutely blissful interpretations of classical guitar pieces. 
Beatrice Popescu: Achenbach is not suggesting a structured scheme such as the one you recommend: PEACE. For our readers, PEACE means: problems, emotions, analysis, contemplation, equilibrium. Lazarus also recommends a scheme called BASIC-ID, while Aaron Beck proposed the model: ABCDE. Regardless of acronyms fashion (also extensively used in corporate world), what prompted you to create your own scheme, with a name so inspiring?

Lou Marinoff: The blunt truth is that HarperCollins, the American publisher of Plato Not Prozac, insisted that I come up with a "method" and an acronym in order to make philosophical counseling more "user-friendly" for an American readership. "Self-help" books are often formulaic for just this reason. So I asked myself a question: "Is it possible that philosophical counseling can be characterized, such that some recognizable pastern or process captures the kind of journey one takes with a counseling philosopher?". In response, I came up with the "PEACE" process during an inspired long-weekend. While it does not describe the specifics of any particular case, I would say that at least $80 \%$ of my cases fit its contours in a general way.

When Plato Not Prozac was published, I knew that I would draw flack from some of my colleagues, for daring to suggest a method. Many of us actually agree with Achenbach, and often we employ the method of no-method. Then again, some philosophical counselors also apply robust methodologies, such as Pierre Grimes's Philosophical Midwifery, or Nelsonian Socratic Dialogue.

Nevertheless, numerous colleagues have remarked to me that the PEACE Process describes, in a general way, a large majority of their cases, too. At the same time, it regularly fails as a purely "self-help" method, as clients usually get stuck at the contemplative stage, and need a philosopher to help them progress beyond it.

The connotation of the acronym is somewhat ironic, in so far as the well-known "Peace Process" in the Middle East appears to be another name for interminable strife. Then again, I firmly believe that all external conflicts are manifestations of inner conflict. Only those whose inner conflicts are resolved can truly be at peace themselves, and therefore with the world.

Beatrice Popescu: Do you still recall your first experience as a counselor? How did it change you, if it happened?

Lou Marinoff: Yes, I recall it vividly. It happened in 1992, at the University of British Columbia's Centre for Applied Ethics. One morning the Centre received a phone call from a high school principal, who sought a practical resolution to an ethical quandary that was causing him and his community considerable distress. Legal advice had succeeded only in making matters worse, while Prozac (self-evidently) would not have resolved the issue either. I took the call, and helped the principal resolve his dilemma via philosophical means - in one session.

The case was a revelation to me - it illustrated that even in a social democracy like Canada, with universal health care and a wide social safety net, people may be suffering from unresolved ethical (among other philosophical) problems, and therefore need access to philosophical counselors.

Beatrice Popescu: How do you think we can match today's pressure to be highly specialized in a certain domain with the need of a more intense and "holistic" paradigm. In other words, how can I be a clinical psychologist trained in cognitive-behavioral therapy working with autistic children and still be able to see this problem in a different context, more global? Aren't we in a "dangerous" need of always having to change what we have already learned, with the risk of eternally redefining the things we know? 
Lou Marinoff: What an important and earnest question! It serves only to deepen my concerns about the SciencesHumanities divide, and the need to bridge this chasm. Had you, as a student of clinical psychology (nominally a "science") been exposed to a course in the Philosophy of Science, you might have been introduced to Neurath's metaphor, which speaks directly to your concern. Here is a summary.

Thanks largely to the work of the late Sir Karl Popper, we now conceive of scientific endeavor as something that progresses not only by discovering truths via experimental verification of hypotheses, but also (and sometimes more importantly) by experimental falsification of mistakenly-held beliefs. Progress in science often depends on identifying and rejecting mistaken theories and false precepts that previous generations had accepted as true. The history of every single science is rife with examples. This is why we have to keep re-writing the scientific textbooks.

What follows is Neurath's metaphor: Scientists are like ship-builders whose vessel is already at sea, and thus they lack the possibility of making repairs in a "safe" and "controlled" dry-dock. Sometimes they must find a way to replace planks, bulkheads, keels, rudders, and propellers while afloat in deep or even turbulent waters, an enterprise that you rightly characterize as "dangerous" or "risky". The alternative - jeopardizing the vessel by allowing it to become unseaworthy - is arguably worse. So scientists must be courageous and skilful enough to constantly repair their ships at sea.

If instead they succumb to inflexible or unchallengeable dogmas, they start looking like religionists.

Beatrice Popescu: Stepping in a young counselor's shoes, do we still have time, nowadays, to take a walk in the antique gardens and contemplate the meaning and scope of life, while the clients await us at the doorstep? Is it possible to write, think and also to have a daily job, all in the same time?

Lou Marinoff: This is a lovely segue from your prior question. If the young counselor in question is a scientist, then indeed she must keep up with her science, and learn to repair her ship at sea. But this in no way precludes (and actually it justifies) her creating space for contemplation. Most of my counseling psychologist colleagues are able to see around five clients per day. If they stretch their caseload to six or seven clients per day (which some of them do toward the end of the week) they become exhausted or even burned out.

Anyone who spends hours at a time being present for others needs to recharge their own batteries - healers also (and sometimes especially) need healing themselves. A wonderful way of achieving this is by strolling through those "antique gardens," partaking in exquisite philosophical blossoms from Aristotle, Epictetus, Lao Tzu, or Shakyamuni. Or perhaps by engaging with music, painting, dance, or writing. Becoming a complete and fulfilled human being requires so much more than being chained to a desk, even in the service of helping others!

Beatrice Popescu: Is the fight with death becoming a daily confrontation in modern society? Do you feel that the collapse of religious institutions in the secular society makes the fear of death more palpable than ever?

Lou Marinoff: You have a knack for asking burning questions, and this is one. As you may know, philosophers like Hobbes and Spinoza, and later, psychologists like Freud and Riviere, accused dogmatic organized religions of preying upon people's infantile fears of the unknown, and especially of death. The "flip-side" is that strong religious convictions can indeed help some people assuage such fears (and at the fanatical extreme, provoke them to murder or suicidal murder). Marx was undeniably correct that religious beliefs function like cultural "opiates," numbing people's primordial fears with faith and hope. 
But since mainstream Judeo-Christian traditions are indeed collapsing, hundreds of millions of Westerners must seek comfort in secular society. This is no mean feat, and difficult to attain without a guiding philosophy.

Beatrice Popescu: Reading Critchley's "Book of Dead Philosophers" it was moving to see how great thinkers deal with the idea of their own mortality. Do you think they were all honest and serene? Thinking of Wittgenstein, he said before dying: "Tell them I've had a wonderful life". Is it reasonable to expect that extensive sessions of philosophical counseling may attenuate the eternal fear of death in humans? Creating legacy can be therapeutic when trying to alleviate the pain of our own death?

Lou Marinoff: Critchley has done a very good job of reminding us that we humans are all-too-cognizant of our mortality, and are at times inconsolable in the face of death. As Critchley points out, many philosophers, from antiquity to the present, have seized upon mortality as a departure point for leading meaningful lives.

Beatrice Popescu: Practical philosophy seems to be working mostly for people with a sense of education and culture. What about the persons who don't understand the paradigm, the simple people who have a narrower understanding of life, how can we touch their souls with philosophy?

Lou Marinoff: If we suppose that philosophy, for the mainstream population, is something of an "acquired taste," then we will not feel obliged to foist our paradigm wholesale upon the masses. Such restraint will happily distinguish us from religious missionaries, who seek (ideally) to convert everyone, and from secular dogmatists, ranging from Marxists to believers in the DSM, who likewise seek to universalize their brands of "snake oil."

That said, human virtues and human decency remain part and parcel of a commodious life, and these lie within reach of most people, external conditions permitting. I shall never forget my Russian grandparents, who escaped the horrors of Tsarist pogroms, the Bolshevik revolution, and the ensuing Civil War, in order to reach the New World, a land that offered them liberty, opportunity, and hope for a better life for their children and grandchildren. They were born and raised in shtetls, and they never read a word of philosophy all their lives. Yet they were courageous, kind, honest, forthright, and hardworking people. One might even venture to say that they did not need philosophy, as their virtues shone brightly without it. They never acquired tastes for Dom Perignon or foie gras either, but this did not get in the way of their goodness ... au contraire!

Beatrice Popescu: In your book "Plato not Prozac" which I must admit I breathlessly read, you don't exclude, but somehow minimize the idea of depression as a brain neurochemistry-induced disorder. Could we take the risk of simply neglecting the idea or is this more of a figure of speech than a programmatic step aiming to provide a panacea-treatment for all types of disorders?

Lou Marinoff: The current pharmacological mantra of "chemical imbalance in the brain" is nothing but a vacuous sales-pitch, used to justify licit drug-dealing on a global scale. The fatuous but unstated background assumption is that brains are "sealed containers" accessible only to pharmacologists, and that consumers are passive and powerless victims of their circumstances and neurochemistry alike. This is a widespread and disempowering swindle.

Consumers need to be reminded that brain-chemistry is affected by a host of factors, including lifestyle choices. Different ways of breathing, eating, working, exercising, recreating, sleeping, thinking, reading, attaining goals, and relating to others all affect our brain chemistry. While indeed there are psychoses and clinical depressions that need to be controlled or diminished by medications, the vast majority of people who depend on mood-enhancing 
formulations have abdicated their sovereignty over their own mental states. Lasting happiness and enduring joie de vivre are among the outcomes of a healthy philosophy of life, and correspondingly healthy lifestyle.

Beatrice Popescu: In the search of solutions for contemporary man's problems, it is obvious we cannot rely exclusively on certain "recipes", pre-packed answers, but more on self-exploration and self-defining efforts, leading to a profound individual construction of the meaning of life. And if the meaning is so intrinsically individual, how is it still possible to communicate to others, how can we still be a "community"? To what extent the individualized meaning of life may be an alienating factor in today's society?

Lou Marinoff: While it may be perfectly obvious to you that a formulaic "paint-by-numbers" modus vivendi cannot be relied on to solve contemporary human problems, it may be less obvious to some of our readers that such approaches are in fact exacerbating the problems themselves, rather than solving them.

During the second half of the $20^{\text {th }}$ century, it became clear that Nietzsche's "will to power," Freud's "will to pleasure," and Riviere's "will to immortality" were not sufficient to account for relentless human purposiveness, and to explicate mechanisms of response to being thwarted. So Frankl introduced "will to meaning" as another prime motivating factor. Beyond this, Nichiren Buddhists have introduced "will to be valued," while philosophical counselors have discovered that "will to be understood without being judged (or diagnosed)" is yet another empirically observable factor.

The individual has been all-but-obliterated, not only by dehumanizing totalitarian governments (political and theocratic alike), but also by the "velvet totalitarianism" of bureaucratic nanny-states, and by the debased technocracies that have colonized education and health care. When people encounter nothing but computer-automated telephone queues or indifferent and incompetent bureaucrats on a daily basis, and when every encounter is quantified according to pre-determined data-sets, and when one's humanity is deemed irrelevant by the system, the meaning of life itself is mocked. We inhabit a Brave New World, in which too many people feel like the last human in a society of robots. Nothing can be more alienating than to have one's individuality and humanity disregarded.

Beatrice Popescu: Talking of communities, the idea of running a Philosophical Café in New York, which I believe you are still very fond of, made you in time more aware of the problems of humans? I see it as a wonderful opportunity to indulge in other's people minds and extract the essence.

Lou Marinoff: Yes, running a Café-Philo in New York was a great experience. I did it monthly, at a Barnes \& Noble bookstore in Chelsea, for about seven years. It taught me a lot about human problems, and never failed to surprise me. Most importantly, it convinced me of the wholesale need to open up a creative and reflective public space, wherein people can air their views and engage in debate with enthusiasm and without fear. The most rewarding aspect was addressing tough issues openly and honestly, without suppression from political correctness, and absent the spin-doctoring of agenda-driven mainstream media.

Beatrice Popescu: I was equally surprised and amused to see that at a recent international conference on philosophical counseling in South Korea you started your presentation on "Well-being in an age of culturally induced illness" with an ironic and iconic outlook on McDonalds dubbed "Hamburger University". Could you develop the subject a little for our readers? 
Lou Marinoff: I can certainly develop this subject. Firstly, the photo in question is a real picture, which I personally took on the campus of "Hamburger University." Only in the USA can such pretentiously self-mocking vulgarity be elevated to commercial seriousness. This "University" campus, located in the outskirts of Chicago, is none other than a McDonalds think-tank. I tried to audit some of its "courses," but was denied entry. I was free to wander around the grounds, and at liberty to pay to stay in the hotel that sits on the campus. This hotel serves very healthy food - e.g. salad bars and Mediterranean-style meals - and there is no McDonald's restaurant (i.e. neither Big Macs nor other fast food) anywhere on the site. So while the mission of "Hamburger University" may well be to help sell another 99 billion Big Macs, its faculty evidently has no intention of consuming such toxic waste themselves. It's an exercise in flagrant hypocrisy, among other things.

At the same time, obesity is now America's \#1 health problem, and the fast-food industry is the problem's biggest instigator. Moreover, juvenile obesity is becoming widespread in all Westernized nations, precisely because of appalling nutritional habits foisted upon children by this industry. Juvenile obesity is a crime against humanity, perpetrated by fast-food and junk-food manufacturers, whose accomplices are none other than parents, schools, and governments.

Now step back and consider that this so-called "epidemic" of obesity is not caused by any viral or bacterial agent. Your children do not "catch" obesity from their obese playmates, as they may well "catch" flu or other biologicallybased illnesses. The epidemic of obesity is an outcome of atrocious eating habits, reinforced by sedentary lifestyles, and a congeries of other cultural factors.

Now step back again, and realize that obesity is only one among many culturally-induced epidemics.

Beatrice Popescu: Have you ever been tempted to switch from academia to the corporate world in an engaged and engaging manner, not only as a public speaker on certain events? What stopped you, if it did?

Lou Marinoff: What an interesting question. I have not yet been tempted to switch, but that's only because of an absence of sufficiently tempting offers. And any temptation factor would have to be correspondingly strong to impel me to make such a change. One of the most rewarding aspects of academic life is its comparatively generous allotment of time to reflective and creative pursuits. One is paid (albeit modestly) to think, to read, and to write. For a philosopher, that's a wonderful way to earn one's keep. The corporate world's rewards are far richer materially, but at the inevitable cost of time. I would rather have less income and more time to pursue my interests, rather than more income and less time, unless the two could somehow be combined. For many years, IBM had a resident "Fellows" program, where a few bright people were paid simply to think about matters of interest to them, under IBM's roof. That kind of investment is bound to pay off sooner or later. So nothing has yet "stopped" me from switching to the private sector, except for the absence, to date, of an offer I couldn't refuse.

Beatrice Popescu: Having noticed your talent as classical guitar player, especially Bach (my favorite classical composer) and your subtle taste for nature photography, I am amazed to witness so many talents in one individual reminding me of a Renaissance man. How do you manage to share yourself between so many passions, what is your relationship with the ruthless god "Time"?

Lou Marinoff: Thanks for your appreciation. "Renaissance Man" would be a nice epitaph, but first I need to complete few more projects. Please don't rush me! I manage to share myself among so many passions because I am driven by one big passion: to live each interval of time (minute, hour, year, lifetime) to the fullest possible 
extent. Or maybe I am excessively passionate? Is that in the DSM-V? But passion alone is not enough; it must also be sublimated into creative art.

Sometimes I can slow time down, and even stop it. But as soon as one expresses the thought "Time has stopped," it starts right up again. On a few occasions I have even turned back the clock; that is, time sent me gifts, from the past into the present. But the future always turned out the same again, except each time it arrived much quicker. My relationship with this ruthless god must be as rueful as possible. As our lives spiral ever-deeper into time's vortex, accelerating as we swirl towards the singularity at the center of our time, we must realize this: The past exists in time, but not in our present time. The future also exists in time, but likewise not in our present time. Only this moment exists in our present time; that is all there is. Death itself is of no-moment. It is not something that happens in any moment of life, except the last one. Why, then, be concerned with it?

When I visited Heliopolis, an Egyptian magus asked me, "Are you master of your time?"

"You already know the answer", I replied. "When we create something..."

He completed my thought: "It creates us".

So just in case time is actually a ruthless goddess, then consecrating every moment to creativity might tempt her to grant even more moments, provided of course that she likes the art.

Beatrice Popescu: At the end of our talk, professor Lou Marinoff, I just want to tell you that I am looking forward to reading your latest book, The Inner Philosopher, written in collaboration with Daisaku Ikeda.

I am deeply honored you offered me the opportunity to interview you, it has been a meaningful experience.

Lou Marinoff: Your thoughtful questions have been stimulating and refreshing. I greatly appreciate your engagement, and hope that you and your readers have enjoyed these responses.

Many thanks too for your interest in The Inner Philosopher. I look forward to reading your review. 